\title{
Investigating demographic processes using innovative combinations of remotely sensed and demographic data
}

\author{
Deborah Balk $^{1} \cdot$ Kathryn Grace ${ }^{2}$
}

Published online: 26 November 2019

(C) Springer Nature B.V. 2019

Using remote-sensed data, largely that from Earth-observing satellites, with demographic data is a relatively new strategy used to improve understanding of population processes occurring across the planet. It may at first seem surprising that a journal dedicated to population and environment interactions warrants a special issue on combining remotely sensed and demographic data to investigate population processes. While adoption of these approaches to understand spatial processes in the social sciences is on the rise, use of remote-sensing data is often a heavier lift than other spatial data or unmeasured but implicit spatial constructs. This is, to a large extent, because it usually requires that demographers or other population-oriented social scientists collaborate with physical scientists such as those in physical geography, climatology, and Earth science. It is the work of such interdisciplinary teams that we are pleased to present in this special issue.

This issue begins with a paper that pays homage to People and Pixels, a National Academy of Sciences study (NRC 1998), commissioned 20 years ago. Kluger and colleagues review the analytical and data landscape with a focus on changes in the scope and scale of available remotely sensed data. They also highlight some of the approaches and applications of remotely sensed data of relevance to social scientists. They provide a primer to new data integration platforms and tools that are helpful, especially for the novice and immediate user and point towards future opportunities. As it is clear from Kluger and colleagues, many questions that intersect populationenvironment are driven not by understanding demographic outcomes but rather by

Deborah Balk and Kathryn Grace contributed equally to this work.

Deborah Balk

Deborah.Balk@baruch.cuny.edu

$\triangle$ Kathryn Grace

klgrace@umn.edu

1 CUNY Institute for Demographic Research, and Marxe School of Public and International Affairs, Baruch College, City University of New York, New York, NY, USA

2 Department of Geography, Environment and Society, Minnesota Population Center, University of Minnesota, Cities, Twin, MN, USA 
using demographic data to understand environmental change. Much empirical research remains to be done to fully exploit the possible uses of the data and to foster collaborations across social sciences that focus on expanding the theoretical aspects of the use and application of remotely sensed data.

In addition to this broad overview article, this special issue includes papers topics well within traditional areas of demographic inquiry - topics closely allied with fertility, mortality, and migration. Two papers examine nutrition and child health in Africa and Asia. Cooper and colleagues examine child health outcomes and food security using survey data and rainfall data derived from remotely sensed data sources. Tobin and colleagues examine child health outcomes using demographic survey data and land use data derived from remotely sensed data. Pinchoff and colleagues investigate preeclampsia, a reproductive health outcome, within the context of increasing salinity and seaward hazards associated with a changing climate. Data for this analysis come from health surveillance data, environmental measures, satellite-derived elevation data of low-elevation coastal zones, and satellite-derived rainfall data in Bangladesh. Also, in Bangladesh, Mueller and Chen analyze cross-border migration from household surveys with respect to satellite-derived measures of flooding and rainfall. These papers, which focus on individual experiences within a given context, highlight the importance of interdisciplinary work for understanding the potential consequences of climate change.

The final paper in our special issue showcases how remote-sensing data can be combined with demographic data to understand macro-level demographic outcomes, in this case urbanization. Onda and colleagues use satellite-derived data (on land cover, builtup areas, and night lights, as well as climate data) as key inputs into a statistical model to estimate urban population growth and growth of urban agglomerations in India. Their novel approach for integrating population and urban areas to understand urbanization can be seen as in invitation to population-environment research community to engage on this important topic: With most of the future population growth to take place in the cities and towns of Asia, Africa and Latin America, it will become increasingly important that demographically-oriented social scientists include spatial paradigms and methods in their tool kit, along with an ability to conceptualize and integrate such data with a full range of population characteristics and processes along an urban continuum.

Despite the diversity of demographic outcomes in this special issue, we note that some mainstream areas remain missing from this issue and others to date remain largely ignored in this interdisciplinary sub-field more broadly. For example, family structure has been a traditional area of inquiry, and one of the earliest adopters of remote-sensed data - with studies of contemporary Amazonia (VanWey et al. 2007; McCracken et al. 1999; De Sherbinin et al. 2008) and Thailand (Entwisle et al. 2005; Rindfuss et al. 2007; Walsh et al. 2013), and historically, the US Great Plains (Gutmann et al. 2005; Gutmann 2000; NRC 2005) — no such papers are represented here. Additionally, aging, an increasingly important aspect of life in the twenty-first century, is not considered in this issue and is rarely considered in the demographic research that uses remotely-sensed data. This lack of attention is glaring considering that the elderly may be disproportionately vulnerable when exposed to a range of conditions (such as temperature extremes, flooding, and food insecurity) that often require the use of remotely-sensed data. We hope that these articles provide a range of empirical examples demonstrating the utility gained from investigating demographic questions by integrating remotely-sensed data, and that in so doing they serve as a motivation for new lines of inquiry. 


\section{References}

De Sherbinin, A., VanWey, L. K., McSweeney, K., Aggarwal, R., Barbieri, A., Henry, S., Hunter, L. M., Twine, W., \& Walker, R. (2008). Rural household demographics, livelihoods and the environment. Global Environmental Change, 18(1), 38-53.

Entwisle, B., Walsh, S. J., Rindfuss, R. R., \& VanWey, L. K. (2005). Population and upland crop production in Nang Rong, Thailand. Population and Environment, 26(6), 449-470.

Gutmann, M. P. (2000). Scaling and demographic issues in global change research: the Great Plains, 18801990. Climatic Change, 44(3), 377-391.

Gutmann, M. P., Deane, G. D., Lauster, N., \& Peri, A. (2005). Two population-environment regimes in the Great Plains of the United States, 1930-1990. Population and Environment, 27(2), 191-225.

McCracken, S. D., Brondizio, E. S., Nelson, D., Moran, E. F., Siqueira, A. D., \& Rodriguez-Pedraza, C. (1999). Remote sensing and GIS at farm property level: demography and deforestation in the Brazilian Amazon. Photogrammetric Engineering and Remote Sensing, 65, 1311-1320.

National Research Council. (1998). People and pixels: linking remote sensing and social science. National Academies Press.

National Research Council. (2005). Population, land use, and environment: research directions. National Academies Press.

Rindfuss, R. R., Entwisle, B., Walsh, S. J., Mena, C. F., Erlien, C. M., \& Gray, C. L. (2007). Frontier land use change: synthesis, challenges, and next steps. Annals of the Association of American Geographers, 97(4), 739-754.

VanWey, L. K., D’Antona, Á. O., \& Brondízio, E. S. (2007). Household demographic change and land use/ land cover change in the Brazilian Amazon. Population and Environment, 28(3), 163-185.

Walsh, S. J., Malanson, G. P., Entwisle, B., Rindfuss, R. R., Mucha, P. J., Heumann, B. W., McDaniel, P. M., Frizzelle, B. G., Verdery, A. M., Williams, N. E., \& Yao, X. (2013). Design of an agent-based model to examine population-environment interactions in Nang Rong District, Thailand. Applied Geography, 39, 183-198.

Publisher's note Springer Nature remains neutral with regard to jurisdictional claims in published maps and institutional affiliations. 